\title{
Study of Fine Needle Aspiration Cytology (FNAC) for Diagnosis of Lesions of Liver Diseases Guided By Ultra Sound
}

\author{
Dr V.Srinivas Kumar ${ }^{1}$, Dr G.Sudhakar ${ }^{2}$ \\ ${ }^{1}$ Assistant Professor, Department Of Pathology, Ghandhi Medical College, Secendrabad, NTRUHS, India \\ ${ }^{2}$ Associate Professor, Department Of Pathology, Guntur Medical College, Guntur, NTRUHS, India
}

\begin{abstract}
The main indication for fine needle aspiration (FNA) of liver is the evaluation of mass lesions.(Silverman JF,Geisinger KR-1996).In most FNA biopsies of hepatic masses an accurate diagnosis can be rendered based on the cytomorphological features alone,(Silverman JF, geisinger KR-1996). However in selected cases, ancillary studies can be quiet helpful in refining the diagnosis.( Silverman JFFinely J L,o'Brein KF 1989). By onsite discussion with radiologists and clinicians, the cytopathologist may gain significant data to integrate into the final diagnosis. The major indication for FNA of the liver is the evaluation of a hepatic mass. FNA biopsy, is especially useful in the investigation of non-neoplastic \& especially neoplastic mass lesions of the liver.
\end{abstract}

Keywords: Diagnosis, FNAC, Liver, ultrasound

\section{Introduction}

FNAC is relatively new technique which was known as far back as in 1833 and is an art that has been updated now(Melcher,1980) ${ }^{[1]}$ The earliest case of FNAC was done in 1833 for a case of infected hydatid cyst at St.Bartholmen's hospital hy Stanley and Earla. Aspiration is a diagnostic procedure was started by Ward in 1912 and followed by Gunthric (1921)for diagnosis of reticulosis ${ }^{[1,2]}$. In 1939,Iverson and Roholm pioneered percutaneous liver core biopsy with a $2.0 \mathrm{~m}$ (outside diameter)needle ${ }^{[3,4]}$. Fine Needle Aspiration of this organ was established by Sodenstorm in 1966 with the examination of 500 cases $^{[4,5]}$.

\section{Material And Methods}

Patients who have been admitted during a period between 2013 to 2015 with suspected liver diseases were subjected to FNAC and cytological assessment.

\subsection{Materials}

1.Cotton and rectified spirit, 2.Disposable needles(22-Gauge), 3.Disposable Syringes, 4.Slides, 5.Glass marking pencil,6.Screw capped bottles containing fixative (Ethyl alcohol and ether).

\subsection{Procedure of aspiration}

Informed consent is obtained from the patient or patient's kin. Along with the clinical work up, platelet count and plasma prothrombin time are estimated to avoid patient's with bleeding tendencies. Patient is also monitored for half an hour after the procedure by monitoring the pulse rate, blood pressure and respiratory distress if any. Anaphylactic tray is always kept at and during the procedure. Fine needle aspiration was performed under ultrasonography guidance on patients diagnosed for nodular or diffuse firm lesions of liver. Clinical data was properly enquired into. These included (1) whether the lesion is single or multiple , associated cirrhosis, concurrent lesions else where in the body especially,colon,gall bladder,breast,pancreas,ascites. Laboratory values like cytology of ascitic fluid and history of malignancy taken into account.

\subsection{Method of aspiration}

The approach for fine needle aspiration was decided by review of ultrasonographic pictures. Aspiration was attempted using a 23-24 guage needle fitted to a 10cc syringe. For deep seated lesions ultrasound guided aspiration using a $90 \mathrm{~mm}$ lumbar puncture of 22 guage was used.

The patient was placed in a supine position. The part to be aspirated was cleaned with spirit swab.The needle was then slowly introduced into the lesion with vacuum created by the retraction of plunger.The needle was gently drawn out and pushed into the lesion repeatedly. The needle was with drawn from the lesion with plunger in its normal position.

The collected material were transferred on to the slide. Then smears were made by gentle pressure between two slides and spread.Routinely, six smears were prepared on labelled slides each time and one of the 
Study Of Fine Needle Aspiration Cytology (Fnac) For Diagnosis Of Lesions Of Liver ...

smears stained by toludine blue was immediately checked for adequacy of the material. Repeated aspirations was done if the material was inadequate or nondiagnostic for malignancy.

The slides were immediately fixed by dipping twice into the fixative and taken out to dry. By this method, fixation is early and at the same time, granular material and aspirated material was prevented from being washed away, which would have happened if slides are directly placed into the fixative and left as such. A gentle pressure was applied over the site of aspirate for few minutes. No dressing is needed.

\subsection{Method of fixing cytological smears}

The slides placed in the fixative were left for a period of 15-30 minutes which is minimum time required for fixation. After this the slides can be left, preferably in refrigerator for any length of time.

\subsection{Method of staining}

After adequate fixation the smears are stained with Ehlrich hematoxylin and Eosin.Other stains used are Papanicoloau, Geimsa, Periodic acid schiff and Reticulin stain where ever necessary.

The stained smears are examined with light microscope. Observations made are recorded. The cytological smears are broadly classified according to Gershergorn et al(1977).

Acellular smear 2.Inflammatory smear 3.Benign smear 4.Malignant smear.

In some of the cases, subsequent biopsies were done and the material is processed as for routine paraffin block and stained with $\mathrm{H} \& \mathrm{E}$.

\section{Results And Observations}

From 2013-2015, the fine needle aspirations of liver were performed on 58 patients. 39 were males and 19 females (table-1). The age ranged from 2 to 92 years (table-2).

In most of the patients FNAC was preceded by ultrasound exam demonstrating one more defects interpreted as suspicious of malignancy. A few patients were suspected of an abscess(Figure 1). On the 58 patients 46 were suspected by malignant lesions and 12 of neoplastic lesions.

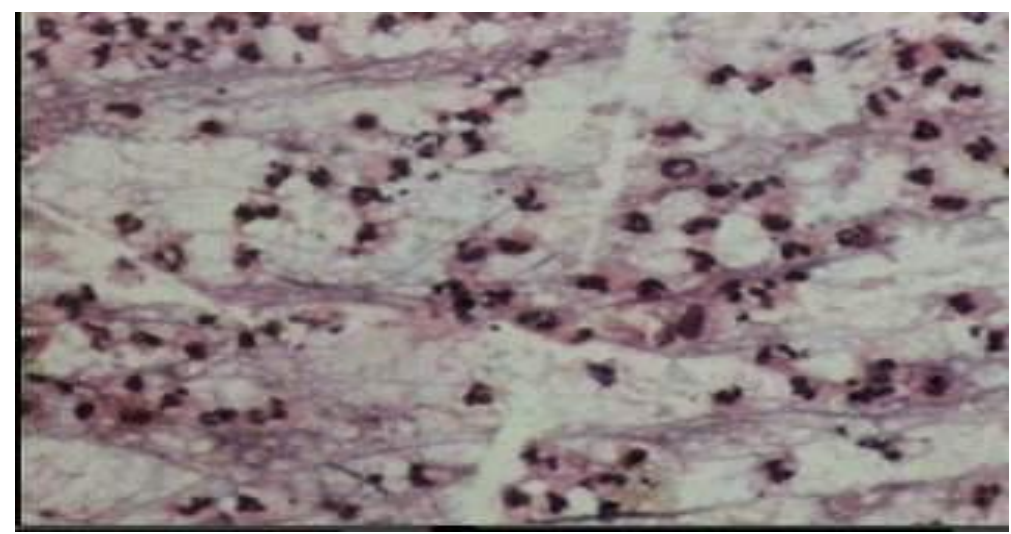

Figure 1: Showing featues suggestive of hepatic abscess (H \& E X 100) of liver.

Of the 46 aspirations performed on patients with suspected malignancy, 36 were diagnosed as positive (78.26\%). They comprised of 26 cases of H.C.C.(Figure.2), 9 cases of secondary deposits( Figure 3,4) and are 1 Hepatoblastoma (table-3).

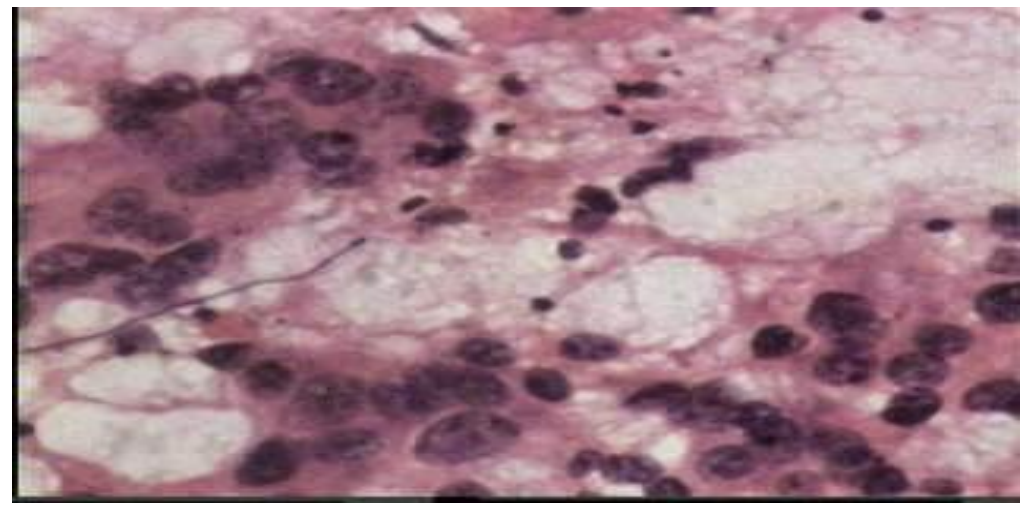

Figure 2: showing features suggestive of pleomorphic large cell hepatocellular carcinoma (H \& E X 100) of liver 


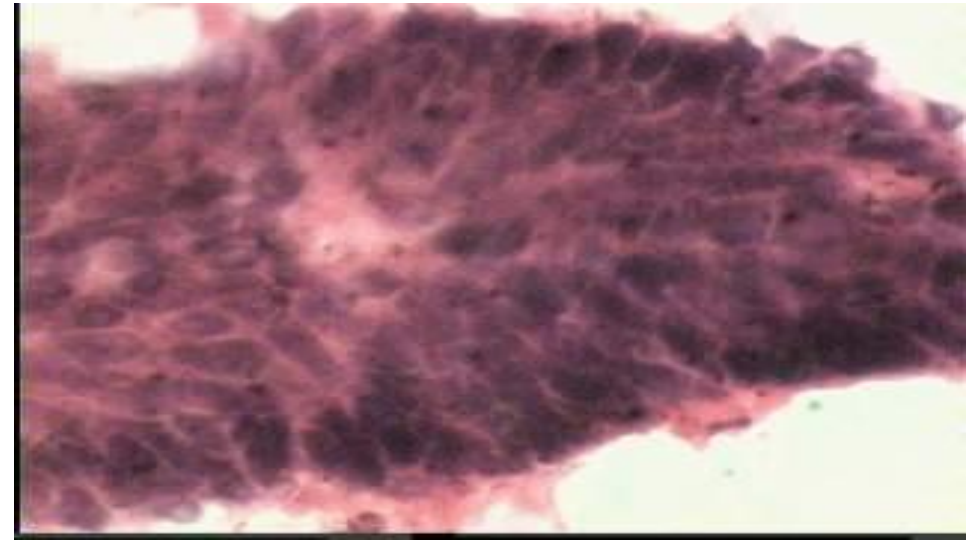

Figure 3 : smears features suggestive of metastatic ? colorectal carcinoma (H \& E X 100) of liver

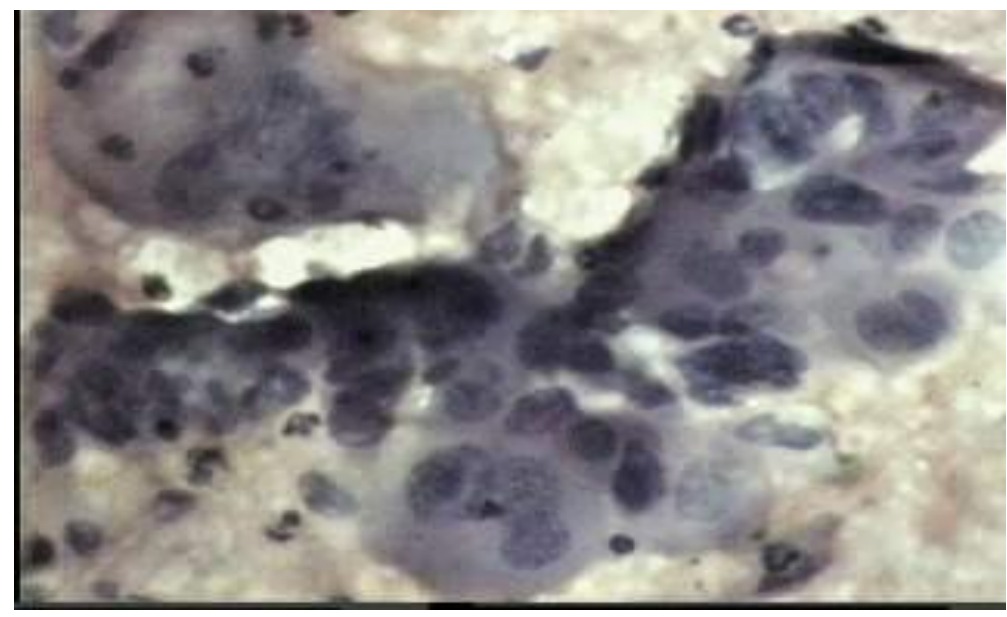

Figure 4: Metastatic poorly differentiated squamous cell carcinoma most probably metastasis from ? carcinoma of cervix. (H \& E X 100) of liver.

On the 12 aspirations performed on patients with a clinical diagnosis of neo-plastic lesion, 7 aspirations were diagnosed are positive $(58.33 \%$ ), they consist of 5 cases of abscess 2 cases of cholestatic hepatitis (table4).

From the above results it is observed that the malignant condition of liver usually yield more material to establish the diagnosis compared to non-neoplastic lesions.

Table-1 Sex Distribution Of Cases

\begin{tabular}{|c|c|}
\hline MALE & FEMALE \\
\hline 39 & 19 \\
\hline
\end{tabular}

Sex Distribution Of Cases

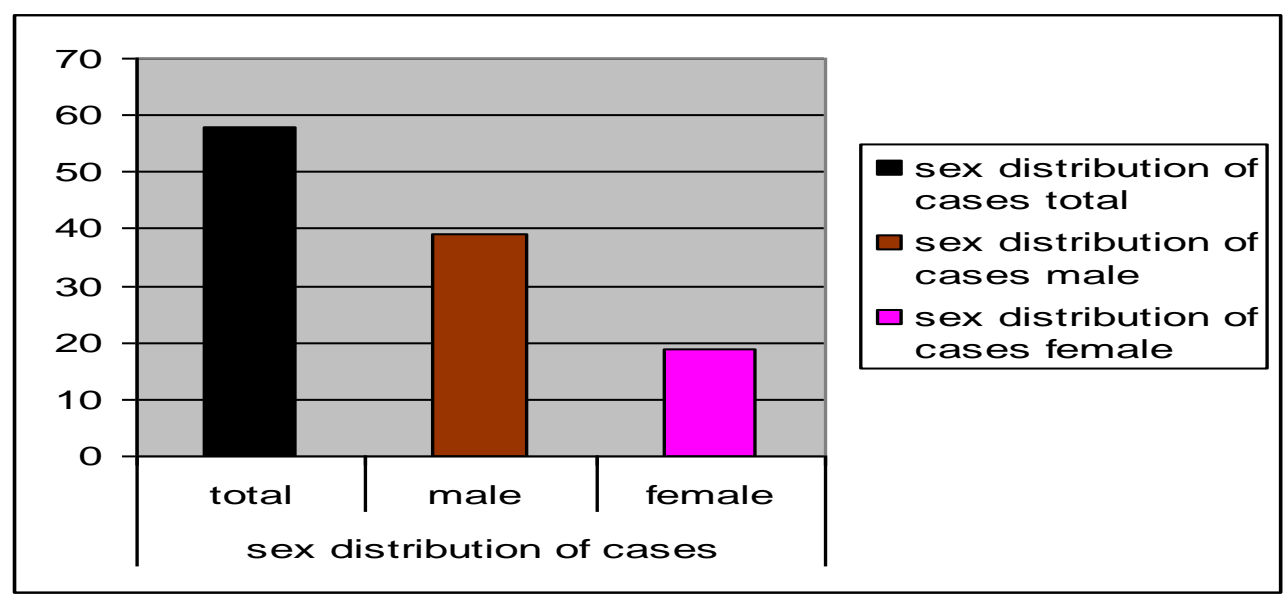


Table-2 Age Distribution Of Cases

\begin{tabular}{|l|l|}
\hline AGE & NO. OF CASES \\
\hline Below20 years & 4 \\
\hline $21-30$ years & 1 \\
\hline $31-40$ years & 5 \\
\hline $41-50$ years & 15 \\
\hline $51-60$ years & 18 \\
\hline $61 \&$ above & 15 \\
\hline
\end{tabular}

Age Distribution Of Cases

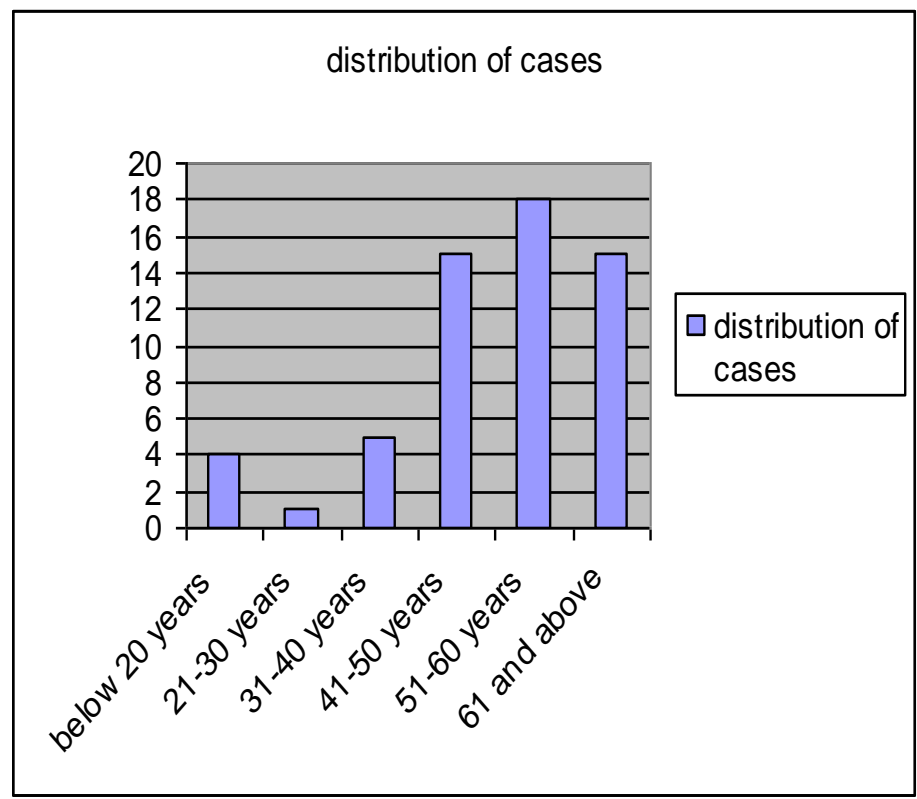

Table-3 Type Of Malignant Lesions

\begin{tabular}{|l|l|l|l|}
\hline CLINICAL DIAGNOSIS & NO. OF ASPIRATIONS & CONFIRMED BY CYTOLOGY & NO OPINION \\
\hline $\begin{array}{l}\text { HEPATOCELLULAR } \\
\text { CARCINOMA }\end{array}$ & 33 & 26 & 7 \\
\hline HEPATOBLASTOMA & 1 & 1 & 0 \\
\hline METASATIC LESIONS & 12 & 9 & 3 \\
\hline TOTAL & 46 & 36 & 10 \\
\hline
\end{tabular}

No conclusive opinions were possible because of inadequate material/not representative of lesions. Sensitivity: $78.26 \%$.

Type Of Malignant Lesions

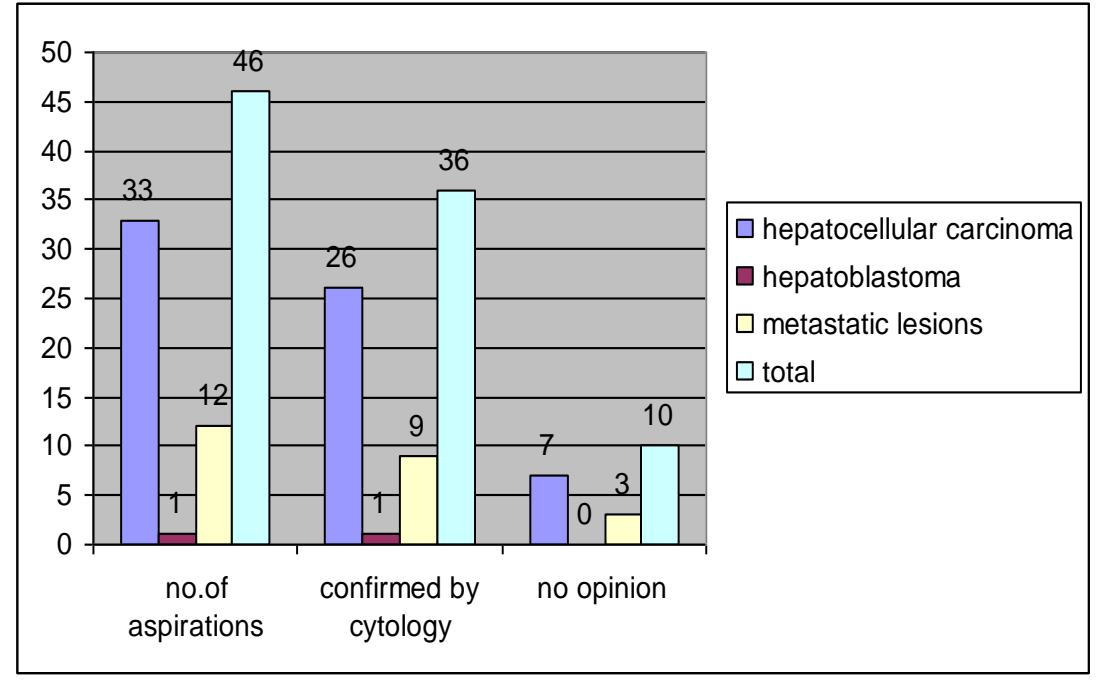


Table-4 Distribution Of Non Neoplastic Lesions

\begin{tabular}{|l|l|l|l|}
\hline CLINICAL DIAGNOSIS & NO. OF ASPIRATIONS & $\begin{array}{l}\text { CONFIRMED } \\
\text { CYTOLOGY }\end{array}$ & NO OPINION \\
\hline ABSCESS & 7 & 5 & 2 \\
\hline CHOLESTATIC HEPATITIS & 4 & 2 & 2 \\
\hline HEMANGIOMA & 1 & 0 & 1 \\
\hline TOTAL & 12 & 7 & 5 \\
\hline
\end{tabular}

Distribution Of Non Neoplastic Lesions

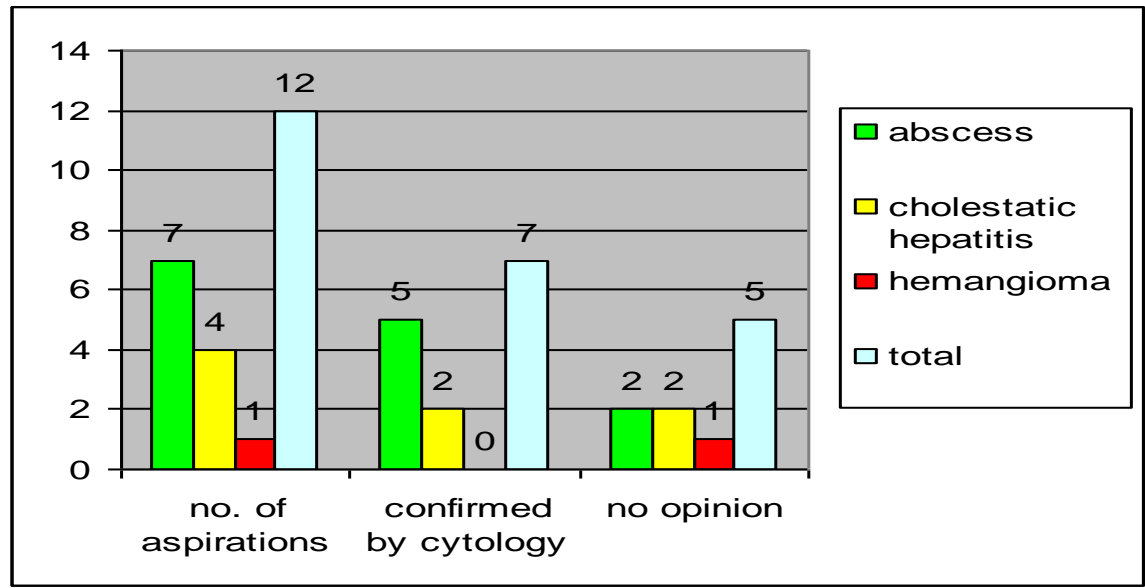

\section{Discussion}

Ultrasonography, CT and magnetic resonance have been widely used in the diagnosis of liver disease, in the past 20 years but the final definite diagnosis of liver space occupying (LSO) lesions cannot be made only by imaging methods. Ultrasonography has been used in combination with fine needle aspiration biopsy in the diagnosis of liver diseases since the 1970 's ${ }^{[12,6,7]}$.

The accuracy of differential diagnosis of liver diagnosis of both benign and malignant lesions could reach $88.8 \%$, since then this technique has become significant in diagnosis of LOS lesions in large hospitals in CHINA. Dr.Edoute reported 279 cases of LSO lesions in 1976-1988 diagnosed by non-ultrasonically guided aspiration biopsy, which is of great importance ${ }^{[8,910]}$.

The thick needle biopsy technique remains indispensable in evaluating many non-neoplastic diseases of liver. However, its sensitivity in detecting malignant lesions of liver is comparatively low. The volume of liver sampled is small, obtained only from a limited, single area. Usually, only one biopsy is obtained.Thus, it is not surprising that high success rates reported with this technique are seen only in cases with extensive liver involvement ${ }^{[11,12,13]}$.

Another disadvantage of thick needle biopsy technique is the risk of complications; include bile peritonitis, hemorrhage, puncture of bowel and even death ${ }^{[1,14]}$. Unlike FNAC, thick needle biopsy is contradicted in cases with ascitis, obstructive jaundice, lesions of left lobe and inaccessible lesions of right lobe.

FNAC overcomes several of these limitations. Although the volume of tissue obtained by FNAC is only about one-tenth that of a thick-needle biopsy, it represents a better sampling of liver since cells and tissue fragments are aspirated from a larger area of liver as the needle is moved up and down during the aspiration. Air dries slides can be rapidly stained, and multiple aspirations can be performed with little risk to the patient ${ }^{[16]}$.

If diagnostic tissue is not obtained on initial aspiration Tao et al reported 34 of 47 positive tumors: multiple aspirations on each patient enabled this group to correctly diagnose carcinoma in all 13 patients even through same individual aspirations were negative. Lundquist, in this series of 2,611 aspirates reported only one serious complication that of an intrahepatic hematoma requiring surgery (Table 5) ${ }^{[17,18,19]}$.

A relatively low positive yield and a higher complication rate associated with the conventional thickneedle biopsy have prompted many clinicians to use FNAC for the diagnosis of intrahepatic neoplasms and to restrict the use of thick-needle biopsy to the few cases in which FNA does not yield sufficient material, especially in non-neoplastic liver disorders.

Early diagnosis and cytomorphologic differentiation of Hepatocellular carcinoma from metastatic carcinoma is of special importance today because of feasibility of surgical resection in some early, selected cases. The reported life expectancy of a patient with an untreated liver cell carcinoma average about six months with effective surgical excision, a possibility of cure exists. Recent advances in chemotherapy also make it more likely that treatment with specific anticancer agents will lead to better survival results ${ }^{[17,18,19]}$. 
The most commonly encountered problem in the interpretation of FNAC is the separation of Hepatocellular carcinoma from reactive, atypical hepatocytes and from metastatic adenocarcinoma.

Our study shows that the important criteria for the diagnosis of Hepatocellular carcinoma are the resemblance of tumor cells to liver cells, frequent prominence of nucleoli; frequent presence of a characteristic trabecular pattern and an aspirate composed of a single cell population. Cellular pleomorphism and anisokaryosis can be seen within the same population of cells, but the tumor cells resemble one another morphologically in terms of nuclear, nucleolar and cytoplasmic characteristics, giving rise to an overall monotonous picture. The reactive hepatocytes, if present on the same smear, are usually topographically separate from the tumor cell aggregates ${ }^{[17,18,20]}$.

In smears obtained from a benign hepatic proliferation, macronucleoli as large as those in Hepatocellular carcinoma can occasionally be seen, but they generally affect individual cells in a random, piecemeal fashion and these atypical cells are often intimately admixed with normal appearing hepatocytes within the same tissue fragment. A transition from normal to mildly atypical to markedly atypical hepatocytes can often be seen in the same aspirate.

These atypical reactive changes impart an impression of cellular pleomorphism and anisokaryosis that may be mistaken for Hepatocellular carcinoma by the unwary. Other cell types, such as benign or reactive ductular cell and inflammatory cells are more frequently encountered in a benign hepatic proliferation ${ }^{[17,19,21]}$.

In cases of Hepatocellular carcinoma, the predominant and sometimes the only cells present could be those from the tumor. The tumor cell nuclei in metastatic adenocarcinoma are generally more pleomorphic with irregular clumping of chromatin. Single or variable numbers of nucleoli can be seen, in contrast to the usually single macronucleolus noted in Hepatocellular carcinoma. The individual tumor cells tend to be columnar, cuboidal, pleomorphic and may form clusters or cell sheets, within which gland like spaces or an organized pattern can be visualized.

In this study, no attempt was made to sub classify H.C.C., however, attempt was made to correlate the cytomorphological features with 3 types of H.C.C will be of practical significance to clinical management.

In this study, there were one false negative reports.a). a case of Hepatocellular carcinoma, in which FNAC revealed necrotic material. The reason being inappropriate material from necrotic core.False negative diagnoses are attributable to (Kline Ts et al) 1.Needle positioning, 2.Necrotic tumor core,3. Focal nature of lesions. Most errors are caused by incorrect placement of the needle. Samples taken inappropriately from necrotic tumor cores may be interpreted as an abscess ${ }^{[12,4,22]}$.

Well differentiated lymphomas may be consfused as an inflammatory lesion and fibrotic neoplasms may yield no tumor cells.

Each from well differentiated H.C.C may be considered as benign hepatocytes. An altered nuclear cytoplasmic ratio, somewhat indistinct nuclear membranes, coarsely clumped chromatin, macronucleoli and prominent endothelial cells play an important role in correct interpretation. Most errors can be circumvented by multiple passes into several sites and avoidance of central necrotic areas ${ }^{[17,23,24]}$.

Table-5 showing Comparision Of Malignant Hepatic Lesions Of Other Workers.

\begin{tabular}{|l|l|l|}
\hline SL NO. & \multicolumn{1}{|c|}{ AUTHOR } & SENSITIVITY \\
\hline 1. & W.B.SCHWERK ET AL & $88.2 \%$ \\
\hline 2. & STEPHEN WHITLACH ET AL & $86.9 \%$ \\
\hline 3. & C.S.HO ET AL & $93.3 \%$ \\
\hline 4. & $\begin{array}{l}\text { TALUKDER SI ET AL MYMENSINGH MEDICAL COLLEGE, } \\
\text { BANGLADESH }\end{array}$ & $93.5 \%$ \\
\hline 5. & $\begin{array}{l}\text { ALLAMA MEDICAL COLLEGE/ JINNAH MEDICAL COLLEGE } \\
\text { AUTHORS LAB,PAKISTAN }\end{array}$ & $74.08 \%$ \\
\hline 6. & PRESENT STUDY & $78.26 \%$ \\
\hline
\end{tabular}

This study indicates the usefulness of FNAC as a sensitive, specific, safe and relatively inexpensive diagnostic procedure in the evaluation of suspected cases of malignant lesions and abscesses of liver.

\section{Conclusions}

58 needle aspirations performed on patients with suspected liver disease. A definite diagnosis of malignancy was made in 36 of the 46 aspirations performed on patients with malignant hepatic disease $(78.26$ $\%)$. There were no false positives. The most common tumors detected were primary carcinoma of liver. Of 12 aspirates performed on non-malignant lesions a definite diagnosis was made in 7 aspirations(58.33\%). No serious complications were encountered as a result of aspiration.

With the help of experienced specialist in imaging, almost all the liver masses can be sampled. However it is essential to keep some smears for special stains and immunocytochemistry. Screening of the smears either unstained or toludine blue stained smears in the imaging room itself, helps in giving satisfactory report avoiding unnecessary delays. It is recommended to prepare cell blocks in all the deep seated masses for 
Study Of Fine Needle Aspiration Cytology (Fnac) For Diagnosis Of Lesions Of Liver ...

histological studies and for immunocytochemistry. Fine Needle Aspiration Cytology of liver lesions appears to be an accurate, safe and relatively inexpensive method for diagnosis.

\section{References}

[1]. Axe SR, Erozan YS, Ermatinger S.V, fine needle aspiration of the live. A comparision of smear and rinse preparation in the detection of cancer. Am J Clin Patol 1986; 86(3):281-285.

[2]. ALI MA , AKTHAR M, MATTINGLY RC: Morphologic spectrum of hepatocellular carcinoma in fine needle aspiration biopsies. Acta Cytol 30:294-302,1986

[3]. ATTENBURY CE, ENRIQUEZRE, DESUTONAGY GI, CONN HO : Comparision of histological and cytological diagnosis of liver biopsies in hepatic cancer. Gastroenterology 76:1352-1357,1979.

[4]. BABB R.R,JACKMAN R.J. Needle biopsy of the liver. A critique of four currently available methods. West J Med 1989; 150(1):39-42.

[5]. BEASLEY RP, HWANG LY, LIN CC, CHIEN CS: hepatocellular carcinoma and hepatitis B virus Lancet 2: 1129-1133,1981.

[6]. BELL, CARR CP, SZYFELBEIN WM: fine needle aspiration cytology of focal liver lesions: results obtained with examination of both cytologic and histologic preparations .Acta Cytol 30: 397-402,1986.

[7]. BERMOIN JJ, MC NEIL RE: cirrhosis with atypia: a potential pitfall in the interpretation of liver aspirates. Acta cytol 32:11-14, 1988.

[8]. COHEN M B,HABER M M,HOLL E A ET AL: cytologic criteria to distinguish hepatocellular carcinoma from nonneoplastic liver. Am J Clin Pathol 1991,95(2):125-130.

[9]. GOODMAN ZD,ISHAK KG,LANGLOSS JM:combined hepatocellular Cholangiocarcinoma: a histological and immunohistochemical study. Cancer 55:124-135,1985

[10]. GREENE C-A,SUEN KC:some cytologic features of hepatocellular carcinoma as seen in fine -needle aspirates.acta cyto 28:713718,1984 .

[11]. HO CS MC LAUGHLIN MJ,TAO LC,BLENDIS L,EVANS WK::guided percutaneous fine needle aspiration biopsy of the liver cancer 47;1781-1785,1981

[12]. JACOBSEN GK,GAMMELGAARD J, FUGLO M: coarse needle biopsy versus fine aspiration biopsy in the diagnosis of focal lesions in the liver. Ultrasonically guided needle biopsy in suspected hepatic malignancy. Acta cytol 27:152-156,1983.

[13]. aspiration biopsy in the diagnosis of focal lesions in the liver. Ultrasonically guided needle biopsy in suspected hepatic malignancy. Acta cytol 27:152-156,1983.

[14]. MAURO MA PARKER L A. Percutaneous drainage of a cystic tumor for relief of pain. South Med j 1987;80(11): 1466.

[15]. NGUYEN GK, Mc HATTIE JD, JEANNOT A :Cytomorphologic aspect of hepatic Angiosarcoma. FNAC of a case. Acta cytol 26: 527-531, 1982

[16]. NAGUCHI SS, YAMAMOTO R, TATSUTA M, KASUGAI H, OKUSDA S, WADA A, TAMURAQ H, :Cell features and pattern in FNAC of hepatocellular carcinoma. Cancer 58: 321-328, 1986

[17]. Pierton M. cytomorphometry of FNAC of liver tumors Patol Po91 1993; 44(4); 193-201

[18]. PERRY MD, JOHNSTON WW: Needle biopsy of liver for diagnosis of non neoplastic liver diseases Acta cytol 29: 385-390, 1985.

[19]. PRASAD N, VERMA N ,PRASAD A ,GUPTA N, journal of cytology 2006; 23 (3) :133-137.

[20]. ROSENBLATT R, KUTCHER R, MOUSSOURIS HF, SHRIEBERK, KOSS LG: Sonographically guided FNAC of liver lesions. JAMA 248 : 1639-1641, 1982.

[21]. SCHWERK WB, SCHMITZ - MOORMANN P : ultra sonically guided FNAC in neoplastic liver diseases : Cytohistologic diagnoses and echo pattern of lesions. Cancer 48 : 1469-1477, 1981.

[22]. SIPPONEN P. PIKKARAINEN P, VOURT E, SALASPOURO M : Copper deposits in FNAC in primary biliary cirrhosis. Acta cytol 24: 203-207, 1980.

[23]. TATSUTA M , YAMMATO R , KASUGAI H ET AL : Cytohistologic diagnosis of the liver by ultrasonically guided FNAC. Cancer 54: 1682-1686, 1984.

[24]. WEE A journal of cytology 2006;23(4): 169-176. 